\title{
Can Bath Ankylosing Spondylitis Disease Activity Index be Affected by Accompanying Fibromyalgia or Depression?
}

\author{
Lale ALTAN, ${ }^{1}$ Yusuf SIVRİĞLU, ${ }^{2}$ İlker ERCAN ${ }^{3}$ \\ ${ }^{1}$ Department of Physical Medicine and Rehabilitation, Medical Faculty of Uludă̆ University, Bursa, Turkey \\ ${ }^{2}$ Department of Psychiatry, Medical Faculty of Uludă̆ University, Bursa, Turkey \\ ${ }^{3}$ Department of Biostatistics, Medical Faculty of Uludağ University, Bursa, Turkey
}

\begin{abstract}
Objectives: This study aims to investigate whether Bath Ankylosing Spondylitis Disease Activity Index (BASDAI) is affected from pathologies such as fibromyalgia (FM) and depression which may coexist in patients with ankylosing spondylitis (AS).

Patients and methods: A total of 170 patients ( 57 males, 123 females; mean age $42.9 \pm 13.0$ years) aged between 18 and 75 years with FM ( $\mathrm{n}=52$ ), depression $(n=60)$ and AS $(n=58)$ were included in the study. All patients were asked to complete BASDAl and Beck Depression Inventory. Percentages of patients with BASDAI scores of $>4$ (cut-off value for disease activity) and $>5$ (cut-off value for reimbursement of biological agents) were calculated and compared between the groups. Individual BASDAI item scores, total BASDAI, and Beck Depression Inventory scores were compared between the groups.

Results: When individual BASDAI items scores were analyzed separately, scores of all items were statistically significantly higher in FM group compared to AS group. While question 1 (fatigue) and 3 (peripheral joint pain and swelling) scores were statistically significantly higher in the depression group compared to AS group, question 5 and 6 scores (items associated with morning stiffness) were significantly lower in the depression group compared to AS group. Percentage of patients with BASDAI scores of $>4$ and $>5$ in the FM group was significantly higher compared to the other two groups. Significant correlation was noted between BASDAI and Beck Depression Inventory scores in AS and FM groups.

Conclusion: Our findings suggest that while assessing disease activity in patients with AS particularly by a patient-reported outcome measure such as BASDAI, other conditions such as FM and depression which may affect the scores should be taken into consideration.

Keywords: Ankylosing spondylitis; Bath Ankylosing Spondylitis Disease Activity Index; depression; fibromyalgia.
\end{abstract}

Ankylosing spondylitis (AS) is a chronic inflammatory disease characterized by inflammatory low back pain and stiffness due to sacroiliac joint and spinal involvement which also affects peripheral joints and extra-articular structures. ${ }^{1}$ Bath Ankylosing Spondylitis Disease Activity Index (BASDAI) is the most frequently recognized tool among those scales that have been developed to assess disease activity in AS. ${ }^{2}$ The index consists of six items questioning patient's fatigue (Q1), severity of neck, back and hip pain (Q2), severity of peripheral joint pain $(\mathrm{Q} 3)$, tenderness on pressure and palpation (Q4), and severity of morning stiffness (Q5 and Q6). A score of 4 has been determined as cut-off value of
BASDAI for assessment of disease activity; that is, BASDAI values of greater than 4 indicate the presence of active disease. Reliability and validity studies have been performed for several versions of the scale in different languages including Turkish. ${ }^{3}$ BASDAI plays significant role in patient follow-up and treatment selection. Social security institution of our country recognizes a cut-off BASDAI score of 5 as an objective parameter for reimbursement of biological agents for the treatment of nearly all patients with AS in our country.

Fibromyalgia (FM) is a chronic musculoskeletal disorder characterized by widespread pain and tender points located in specific body

Received: April 01, 2014 Accepted: July 09, 2014 Published online: January 13, 2015

Correspondence: Lale Altan, M.D. Uludağ Üniversitesi Tıp Fakültesi, Fiziksel Tıp ve Rehabilitasyon Anabilim Dalı, 16059 Görükle, Bursa, Turkey.

Tel: +90 224 - 2347691 e-mail: lalealtan@gmail.com

๑)2015 Turkish League Against Rheumatism. All rights reserved. 
regions. ${ }^{4}$ Although FM may occur as a primary syndrome, it may also accompany several rheumatic conditions including systemic lupus erythematosus, rheumatoid arthritis and AS. ${ }^{4}$ Symptoms such as fatigue, sleep disorders, morning stiffness, subjective swelling in hands and feet may commonly be present in addition to pain in patients with FM. Thus, some symptoms such as fatigue, morning stiffness, and tenderness on palpation which are questioned and assessed by several items of BASDAI may also be present in FM.

Depression is defined as a psychological disorder characterized by negative mood, desperation and hopelessness. ${ }^{5}$ Epidemiological studies have shown that mood disorders are more common in patients with chronic pain. ${ }^{6}$ Pain, restriction of motion, and other functional losses due to disease-related deformities may be expected to lead to psychiatric disorders, particularly depression in patients with AS deformities. While chronic pain is known to cause depression, pain-related symptoms are also known to be more common in people with depression. ${ }^{7}$ High BASDAI scores which may be reported by AS patients with depression may cause inaccurate assessment of disease activity and mislead the clinician for advanced treatment decisions with biological agents.

The aim of this study was to investigate whether BASDAI is affected from pathologies such as FM and depression which may coexist in patients with AS.

\section{PATIENTS AND METHODS}

A total of 170 patients (57 males, 123 females; mean age $42.9 \pm 13.0$ years) who were aged between 18 and 75 years, admitted to rheumatology and psychiatry outpatient clinics of Uludağ University Medical Faculty, and treated due to FM (52 females; mean age 51.3 \pm 8.8 years), depression (17 males, 43 females; mean age $38.0 \pm 12.6$ years) and AS (40 males, 18 females; mean age $40.5 \pm 13.0$ years) were included. Inclusion criteria were diagnosis of FM according to American College of Rheumatism criteria, diagnosis of AS according to modified New York criteria, and major depression or dysthymic disorder according to the American Psychiatric Association's Diagnostic and Statistical Manual,
Fourth Edition (DSM IV) criteria. Patients with coexisting musculoskeletal and/or psychiatric disorders other than their study-related diagnoses were excluded in each patient group. The study was approved by the local ethical board and written informed consent was obtained from all patients before inclusion in the study.

All patients were asked to complete BASDAI. Diagnosis of the patients in the depression group was already made according to DSM IV criteria. However, all patients in all groups were also requested to fill the Beck Depression Inventory (BDI) to assess the relationship between depression symptoms and BASDAI. Percentage of patients with BASDAI scores of $>4$ (cut-off value for disease activity) and $>5$ (cut-off value for reimbursement of biological agents) were calculated and compared between the groups. Since all patients in FM group were females, a subgroup analysis was done separately by calculating the percent of the patients with BASDAI scores $>4$ and $>5$ among the 19 female patients in AS group and comparing them with FM group. Individual BASDAI item scores, total BASDAI, and BDI scores were also compared between the groups.

\section{Statistical analysis}

Normal distribution of data was tested using Shapiro-Wilk test. Between-group comparisons were performed using Kruskal-Wallis test. Categorical data were compared using Chi-square test. Spearman correlation analysis was performed between scale scores and the results were reported as Spearman's rank correlation coefficient. Descriptive value was defined as mean \pm standard deviation for data with normal distribution, and as median \pm minimum-maximum for data without normal distribution.

\section{RESULTS}

Fibromyalgia group was significantly older than the other two groups $(p<0.001)$. Comparison of age, individual BASDAI item scores, total BASDAI and BDI scores between the three groups are presented in Table 1. Mean BASDAI score in the FM group was significantly higher compared to the AS and depression groups. There was no statistically significant difference 
Table 1. Comparison of age, Bath Ankylosing Spondylitis Disease Activity Index item scores, total Bath Ankylosing Spondylitis Disease Activity Index score and Beck Depression Inventory score between patient groups

\begin{tabular}{|c|c|c|c|c|c|c|c|c|c|c|c|c|}
\hline & \multicolumn{3}{|c|}{ Fibromyalgia $(\mathrm{n}=52)$} & \multicolumn{3}{|c|}{ Depression $(n=60)$} & \multicolumn{3}{|c|}{ Ankylosing spondylitis $(\mathrm{n}=58)$} & \multirow[b]{2}{*}{$p$} & \multirow[b]{2}{*}{ Significance } & \multirow[b]{2}{*}{$p$} \\
\hline & Median & Range & Mean \pm SD & Median & Range & Mean \pm SD & Median & Range & Mean \pm SD & & & \\
\hline Age & & & $51.3 \pm 8.8$ & & & $38.0 \pm 12.6$ & & & $40.5 \pm 13.0$ & $<0.001$ & $\begin{array}{l}\text { FM-Depression } \\
\text { FM-AS } \\
\text { Depression-AS }\end{array}$ & $\begin{array}{r}<0.001 \\
<0.001 \\
0.256\end{array}$ \\
\hline Q1 & 6.85 & $0-10$ & & 6.85 & $0-10$ & & 3.15 & $0-10$ & & $<0.001$ & $\begin{array}{l}\text { FM-Depression } \\
\text { FM-AS } \\
\text { Depression-AS }\end{array}$ & $\begin{array}{r}0.759 \\
<0.001 \\
<0.001\end{array}$ \\
\hline Q2 & 7.95 & $0.90-10$ & & 5.40 & $0-10$ & & 4.40 & $0-10$ & & $<0.001$ & $\begin{array}{l}\text { FM-Depression } \\
\text { FM-AS } \\
\text { Depression-AS }\end{array}$ & $\begin{array}{r}<0.001 \\
<0.001 \\
0.349\end{array}$ \\
\hline Q3 & 5.35 & $0-10$ & & 2.20 & $0-9.20$ & & 0.70 & $0-9.20$ & & $<0.001$ & $\begin{array}{l}\text { FM-Depression } \\
\text { FM-AS } \\
\text { Depression-AS }\end{array}$ & $\begin{array}{r}0.001 \\
<0.001 \\
0.008\end{array}$ \\
\hline Q4 & 6.45 & $0.80-10$ & & 2 & $0-8.30$ & & 1.65 & $0-10$ & & $<0.001$ & $\begin{array}{l}\text { FM-Depression } \\
\text { FM-AS } \\
\text { Depression-AS }\end{array}$ & $\begin{array}{r}<0.001 \\
<0.001 \\
0.739\end{array}$ \\
\hline Q5 & 7.40 & $0-10$ & & 0.70 & $0-9$ & & 2.20 & $0-10$ & & $<0.001$ & $\begin{array}{l}\text { FM-Depression } \\
\text { FM-AS } \\
\text { Depression-AS }\end{array}$ & $\begin{array}{r}<0.001 \\
<0.001 \\
0.001\end{array}$ \\
\hline Q6 & 3.75 & $0-10$ & & 0.20 & $0-10$ & & 1.25 & $0-10$ & & $<0.001$ & $\begin{array}{l}\text { FM-Depression } \\
\text { FM-AS } \\
\text { Depression-AS }\end{array}$ & $\begin{array}{r}<0.001 \\
<0.001 \\
0.024\end{array}$ \\
\hline Total & 6.19 & $2.17-9.85$ & & 3.75 & $0-7.88$ & & 2.60 & $0-9.14$ & & $<0.001$ & $\begin{array}{l}\text { FM-Depression } \\
\text { FM-AS } \\
\text { Depression-AS }\end{array}$ & $\begin{array}{r}<0.001 \\
<0.001 \\
0.019\end{array}$ \\
\hline Beck & 13 & $1-39$ & & 26 & $9-45$ & & 8.50 & $0-40$ & & $<0.001$ & $\begin{array}{l}\text { FM-Depression } \\
\text { FM-AS } \\
\text { Depression-AS }\end{array}$ & $\begin{array}{r}<0.001 \\
0.031 \\
<0.001\end{array}$ \\
\hline
\end{tabular}

between depression and AS groups in terms of mean BASDAI scores.

When individual BASDAI item scores were analyzed separately, scores of all items were significantly higher in FM group compared to AS group. While Q1 (fatigue) and Q3 (peripheral joint pain and swelling) scores were significantly higher in the depression group compared to AS group, Q5 and Q6 scores (items associated with morning stiffness) were significantly lower in the depression group compared to AS group.
Percentage of patients with BASDAI score of $>4$ (cut-off value for active disease) was $86.5 \%$ in the FM group, $41.7 \%$ in the depression group, and $29.3 \%$ in the AS group. Percentage of patients with BASDAI score of $>4$ in the FM group was significantly higher compared to the other two groups. There was no statistically significant difference between depression and AS groups (Table 2).

Percentage of patients with BASDAI score of $>5$ (cut-off value for reimbursement of biological agents) was $71.2 \%$ in the FM group, $28.3 \%$

Table 2. Comparison of percentage of patients with Bath Ankylosing Spondylitis Disease Activity Index score $\geq 4$ (cutoff value for disease activity)

\begin{tabular}{|c|c|c|c|c|c|c|c|}
\hline & \multicolumn{2}{|c|}{ BASDAI <4 (n=83) } & \multicolumn{2}{|c|}{ BASDAI $\geq 4(n=87)$} & \multirow[b]{2}{*}{$p$} & \multirow[b]{2}{*}{ Significance } & \multirow[b]{2}{*}{$p$} \\
\hline & $\mathrm{n}$ & $\%$ & $\mathrm{n}$ & $\%$ & & & \\
\hline Fibromyalgia & 7 & 13.5 & 45 & 86.5 & & FM-Depression & $<0.001$ \\
\hline Depression & 35 & 58.3 & 25 & 41.7 & $<0.001$ & FM-AS & $<0.001$ \\
\hline Ankylosing spondylitis & 41 & 70.7 & 17 & 29.3 & & Depression-AS & $=0.161$ \\
\hline
\end{tabular}


in the depression group, and $22.4 \%$ in the AS group. Percentage of patients with BASDAI score of $>5$ in the FM group was significantly higher compared to the other two groups.

The subgroup analysis for 18 female patients in AS group showed that percentage of patients with BASDAI score of $>4$ was $57.9 \%$, and percentage of patients with BASDAI score of $>5$ was $22.4 \%$. Percentage of patients with BASDAI score of $>4$ and $>5$ in the FM group was also significantly higher compared to the female AS subgroup.

Results of correlation analysis between BASDAI and BDI scores for each patient group are presented in Table 3. Significant correlation was noted between BASDAI and BDI scores in AS and FM groups.

\section{DISCUSSION}

We have demonstrated that FM patients have higher BASDAI scores compared to AS patients. To our knowledge, currently there are no specific objective tests to determine disease activity in patients with AS. Although AS is an inflammatory disorder, acute phase reactants such as C-reactive protein and erythrocyte sedimentation rate that are known to be highly correlated with disease activity in other inflammatory disorders including rheumatoid arthritis are not sufficient to determine disease activity in AS. ${ }^{8}$ BASDAI has been developed to meet the need for determining disease activity in AS and has become the most widely used activity indicator both in routine clinical practice as well as drug trials since its implementation in 1994. ${ }^{2,9}$ However, BASDAI is inherently a self-reported questionnaire which does not include any objective parameters. Increasingly more authors believe that it reflects only some part of disease activity and is not adequately sensitive to changes, thus there has been an ongoing search for novel activity indices. ${ }^{10}$ Although a new scale called Ankylosing Spondylitis Disease Activity Score which includes objective parameters such as $\mathrm{C}$-reactive protein or erythrocyte sedimentation rate has been developed,,$^{10} \mathrm{BASDAI}$ still continues to be widely used in clinical practice and serves as the most important end-point in clinical trials in which the efficacy of novel drugs are tested. ${ }^{9}$ Actually, the high BASDAI scores that we have noted in FM patients is not an unexpected finding since items questioning fatigue (Q1), pain (Q2), and morning stiffness (Q5-6) are the most common symptoms of FM. In a previous study, Heikkilä et al. ${ }^{11}$ have compared functional impairment and disease activity in spondyloarthropathy and FM patients using functional indices and BASDAI, respectively. They have found that BASDAI scores were statistically significantly higher in FM group compared to spondyloarthropathy group. Personal health state scores of FM patients were also lower compared to those of AS. FM does not lead to inflammation or joint destruction; however, these patients demonstrate relatively lower pain threshold and tolerance levels in response to thermal and electrocutaneous stimulation. ${ }^{12}$ These findings suggest that musculoskeletal system is not the only cause of pain in patients with FM, and that a complex pathogenesis including central mechanisms are involved. Therefore, high scores may be expected in pain-related items of BASDAI. Practically speaking, this issue leads to the question of how the severity of symptoms associated with true inflammation will be measured in AS patients with accompanying FM. FM is known to be a common coexisting condition in patients with rheumatoid arthritis and systemic

\begin{tabular}{|c|c|c|c|c|c|c|c|}
\hline & Q1 & Q2 & Q3 & Q4 & Q5 & Q6 & Total \\
\hline \multicolumn{8}{|c|}{ Fibromyalgia } \\
\hline r & 0.340 & - & - & - & 0.320 & 0.347 & 0.388 \\
\hline$p$ & 0.014 & 0.153 & 0.153 & 0.127 & 0.021 & 0.012 & 0.004 \\
\hline \multicolumn{8}{|c|}{ Depression } \\
\hline $\mathrm{r}$ & - & - & - & - & - & - & - \\
\hline $\mathrm{p}$ & 0.871 & 0.582 & 0.997 & 0.825 & 0.136 & 0.524 & 0.946 \\
\hline \multicolumn{8}{|c|}{ Ankylosing spondylitis } \\
\hline r & 0.450 & 0.378 & 0.461 & 0.594 & 0.472 & 0.359 & 0.543 \\
\hline $\mathrm{p}$ & $<0.001$ & 0.003 & $<0.001$ & $<0.001$ & $<0.001$ & 0.006 & $<0.001$ \\
\hline
\end{tabular}


lupus erythematosus. ${ }^{13} \mathrm{FM}$ has also been reported to accompany several spondyloarthropathies with a prevalence of $24 \%$ in psoriatic arthritis and $49 \%$ in Crohn's disease. ${ }^{14}$ Limited data exist regarding the prevalence of FM in patients with AS. In their cross-sectional study, Almodóvar et al. ${ }^{15}$ have reported that accompanying FM was present in $4.11 \%$ of 462 AS patients, and this rate was raised up to $10.83 \%$ when only females were included in the analysis. On the contrary, Aloush et al. ${ }^{16}$ have reported that FM was present in half of females with AS. Both studies have indicated that high BASDAI scores were strongly associated with the presence of FM. The most important problem related to this situation which is also compatible with the findings of our study is that it may lead to overtreatment of patients. In daily practice, physicians rely on BASDAI when considering medical treatment alternatives. The social insurance institute which is responsible from coverage of medical expenses of nearly all patients in our country reimburses treatment with expensive biological agents only for patients with BASDAI score of over 5. We have found that $71.2 \%$ of patients with FM had BASDAI score over 5. In other words, BASDAI score may misinform both the physician and the social insurance institute and lead to significant material and moral losses due to unnecessary treatment if accompanying FM is overlooked in AS patients.

We have noted a slightly higher mean total BASDAI score, which did not reach statistical significance, in patients with depression compared to patients with AS. Moreover, BASDAI score was over the cut-off value for active disease in about one quarter of patients with depression. Pain is one of the most frequently reported symptoms in patients with depression. ${ }^{17}$ While chronic pain may lead to depression, depression may itself increase pain perception. ${ }^{18}$ Monoamine transmitters such as serotonin and noradrenaline are known to play role in the pathophysiology of depression. Since the descending serotonergic and noradrenergic pathways arise from the same neurons as the central pathways, namely the raphe nucleus and the locus coeruleus, a dysfunction that results in the emotional and vegetative symptoms of depression is also likely to cause dysfunction of the descending inhibitory pathways. Therefore, most depressive patients may complain of fatigue and lack of energy in addition to headaches, abdominal pain and musculoskeletal pain. It has been reported in one study that $69.1 \%$ of patients with major depression had at least moderate level of pain symptom. ${ }^{19}$ Symptoms including chronic pain, functional losses, social isolation, and sexual dysfunction can be expected to lead to depression in patients with AS. Using BDI as an assessment tool, we have previously shown that depression was present in $14.3 \%$ of patients with AS. ${ }^{20}$ Barlow et al. ${ }^{21}$ have reported that one third of patients with AS had a relatively high level of depressive symptoms and that this rate was even higher for women AS patients. Although different prevalence rates of depression have been reported in patients with AS, the question we have raised, as has been stated in the introduction, was whether depression had an influence on BASDAI scores. Our results have shown that there was a significant correlation between BDI and BASDAI scores in AS and FM patients. Previous studies investigating the relationship between depression and disease activity in AS have also revealed similar results. ${ }^{22,23}$ As a result of our findings, we suggest that assessment of disease activity in patients with AS particularly by a patient-reported outcome measure such as BASDAI must include assessment of depression, which may potentially affect these scores. We recommend that treatment decisions and alterations should be made after treatment of accompanying depression if noted.

The most important limitation of this study was the significant difference of sex distribution of the study groups. Our results have most probably been influenced from this imbalance. The fact that AS is more prevalent in males, while FM and depression are more common in females has led to this imbalance and has unfortunately prevented us to form homogeneous groups. However, the subgroup analysis done by comparing the female AS patients with the all-female FM group showed definite similarity to the former results. The second limitation is the significant age difference between the FM group and the other two groups. This was because there was no age limit among our inclusion criteria.

Despite these weaknesses, our study is, to our knowledge, the first study which emphasizes that critical treatment decisions should not be based exclusively on BASDAI scores, but potential factors which may influence these scores should also be taken into account. We believe that further 
studies involving greater number of patients and more homogeneous groups may provide answers to questions we have raised or encourage further questions to be asked regarding this issue.

\section{Declaration of conflicting interests}

The authors declared no conflicts of interest with respect to the authorship and/or publication of this article.

\section{Funding}

The authors received no financial support for the research and/or authorship of this article.

\section{REFERENCES}

1. Khan MA. Ankylosing spondylitis: introductory comments on its diagnosis and treatment. Ann Rheum Dis 2002;61:3-7.

2. Garrett S, Jenkinson T, Kennedy LG, Whitelock H, Gaisford P, Calin A. A new approach to defining disease status in ankylosing spondylitis: the Bath Ankylosing Spondylitis Disease Activity Index. J Rheumatol 1994;21:2286-91.

3. Akkoc Y, Karatepe AG, Akar S, Kirazli Y, Akkoc N. A Turkish version of the Bath Ankylosing Spondylitis Disease Activity Index: reliability and validity. Rheumatol Int 2005;25:280-4.

4. Bradley LA, Alarcon GS. Fibromyalgia. In: Kopman WJ, editor. Arthritis and allied conditions. Philadelphia: Lippincott Williams \& Wilkins; 2001. p. 1811-44.

5. Linton SJ, Sofia Bergbom S. Understanding the link between depression and pain. Scan $J$ Pain 2011;2:47-54.

6. Demyttenaere K, Reed C, Quail D, Bauer M, Dantchev $\mathrm{N}$, Montejo AL, et al. Presence and predictors of pain in depression: results from the FINDER study. J Affect Disord 2010;125:53-60.

7. Gambassi G. Pain and Depression Chicken and Egg Problem Revisited. Arch Gerontol Geriatr 2009;Suppl 1:103-12.

8. de Vlam K. Soluble and tissue biomarkers in ankylosing spondylitis. Best Pract Res Clin Rheumatol 2010;24:671-82.

9. Zochling J. Measures of symptoms and disease status in ankylosing spondylitis: Ankylosing Spondylitis Disease Activity Score (ASDAS), Ankylosing Spondylitis Quality of Life Scale (ASQoL), Bath Ankylosing Spondylitis Disease Activity Index (BASDAI), Bath Ankylosing Spondylitis Functional Index (BASFI), Bath Ankylosing Spondylitis Global
Score (BAS-G), Bath Ankylosing Spondylitis Metrology Index (BASMI), Dougados Functional Index (DFI), and Health Assessment Questionnaire for the Spondylarthropathies (HAQ-S). Arthritis Care Res (Hoboken) 2011;63 Suppl 11:S47-58.

10. Lukas C, Landewé R, Sieper J, Dougados M, Davis J, Braun J, et al. Development of an ASAS-endorsed disease activity score (ASDAS) in patients with ankylosing spondylitis. Ann Rheum Dis 2009; 68:18-24.

11. Heikkilä S, Ronni S, Kautiainen HJ, Kauppi MJ. Functional impairment in spondyloarthropathy and fibromyalgia. J Rheumatol 2002;29:1415-9.

12. Arroyo JF, Cohen ML. Abnormal responses to electrocutaneous stimulation in fibromyalgia. J Rheumatol 1993;20:1925-31.

13. Yunus MB. The prevalence of fibromyalgia in other chronic pain conditions. Pain Res Treat 2012;2012:584573.

14. Buskila D, Odes LR, Neumann L, Odes HS. Fibromyalgia in inflammatory bowel disease. $\mathrm{J}$ Rheumatol 1999;26:1167-71.

15. Almodóvar R, Carmona L, Zarco P, Collantes E, González C, Mulero J, et al. Fibromyalgia in patients with ankylosing spondylitis: prevalence and utility of the measures of activity, function and radiological damage. Clin Exp Rheumatol 2010;28:33-9.

16. Aloush V, Ablin JN, Reitblat T, Caspi D, Elkayam O. Fibromyalgia in women with ankylosing spondylitis. Rheumatol Int 2007;27:865-8.

17. Robinson MJ, Edwards SE, Iyengar S, Bymaster F, Clark M, Katon W. Depression and pain. Front Biosci 2009;14:5031-51.

18. Gambassi G. Pain and depression: the egg and the chicken story revisited. Arch Gerontol Geriatr 2009;49:103-12.

19. Gameroff M, Olfson M. Major depressive disorder, somatic pain, and health care costs in an urban primary care practice. J Clin Psychiatry 2006;67:1232-9.

20. Altan L, Bingol U, Sarandöl A, Aslan M, Ercan İ. Ankilozan spondilitli hastalarda anksiyete ve depresyon. Romatoloji ve Tibbi Rehabilitasyon 2003;14:221-7.

21. Barlow JH, Macey SJ, Struthers GR. Gender, depression and ankylosing spondylitis. Arthritis Care Res 1993;6:45-51.

22. Martindale J,Smith J, Sutton CJ, Grennan D, Goodacre L, Goodacre JA. Disease and psychological status in ankylosing spondylitis. Rheumatology 2006; 45:1288-93.

23. Baysal O, Durmuş B, Ersoy Y, Altay Z, Senel K, Nas $\mathrm{K}$, et al. Relationship between psychological status and disease activity and quality of life in ankylosing spondylitis. Rheumatol Int 2011;31:795-800. 